\section{Heart rate and skin conductance responding during three attention-direction tasks under distraction conditions}

\author{
ROSS W. BUCK, ROBERT E. MILLER, and WILLIAM F. CAUL* \\ University of Pittsburgh, School of Medicine, Pittsburgh, Pa. 15213
}

This study investigated the possibility that a failure to find cardiac acceleration to an environmental rejection task in a previous study was due to insufficient distraction in the experimental situation. The study was replicated, with distracting events added. An environmental intake task was associated with heart-rate deceleration during the first $60 \mathrm{sec}$. The rejection task and a third task involving attention to bodily events were not associated with significant heart-rate change. There were no differences in skin-conductance responding to the three tasks.

Lacey has proposed that tasks which demand attention to environmental events ("environmental intake" tasks) are associated with cardiac deceleration, and that tasks which demand a preoccupation with cognitive events and consequently require inattention to distracting environmental stimuli ("environmental rejection" tasks) are associated with cardiac acceleration (Lacey, 1959; Lacey et al, 1963). Campos \& Johnson (1966, 1967) and Johnson \& Campos (1967) argue that the accelerations to rejection tasks observed by Lacey were due to the operation of a different variable: verbalization. Buck et al (1969) investigated the heart-rate and skin-conductance response to three attention-direction tasks with no verbalization requirement. That study showed cardiac deceleration to an acceptance task of looking at a series of slides but no heart-rate change to a rejection task of remembering events of the day before. It was concluded that this was consistent with the views of Campos and Johnson regarding the importance of verbalization in producing cardiac acceleration to rejection tasks.

Another factor, however, could have accounted for this lack of change in the Buck et al rejection task. According to Lacey's model, the heart-rate acceleration accompanying environmental rejection is a response to the need to shut out distracting environmental events. Supporting the importance of the distraction variable, Gibson \& Hall (1966) found acceleration to a mental task only when white noise was present, and Steele \& Koons (1968) found greater acceleration to a mental arithmetic

* Now at Vanderbilt University. This investigation was supported by Research Grant MH-00487 from the National Institute of Mental Health of the National Institutes of Health. U.S. Public Health Service, and by the Commonwealth of Pennsylvania. task with white noise than without. In the previous experimental situation, Ss were in a relatively quiet setting with no obvious distractions. Accordingly, it is possible that the failure to find $H R$ acceleration to the rejection task in that study might have been due to the lack of distracting stimuli in the environment that would place demands on the $S$ to shut out environmental events. To test this hypothesis, a second experiment was designed to include a more distracting environment during the tasks.

As in the previous study, a third attention-direction task was included that was neither an obvious rejection task nor an acceptance task-that of concentrating on one's internal bodily events. In the previous study this condition was associated with cardiac deceleration, task. However, it was also associated with lower skin-conductance measures and it was rated as being more difficult than the other tasks. The task was included in this experiment to explore its effects on physiological responding under distraction conditions.

\section{SUBJECTS}

The Ss were 18 male undergraduates suggesting that it may be an acceptance recruited and paid $\$ 2.50$ through the student-employment service at the University of Pittsburgh.

PHYSIOLOGICAL MEASURES

Heart rate (HR) and skin conductance (SC) were monitored by a Grass Model 7 polygraph equipped with a Model 7P5A wide-band ac preamplifier for $H R$ measurement and a Model 7P1A low-level dc preamplifier for SC measurement. Skin-conductance measurement was accomplished by $1 / 4$-in-diam zinc electrodes attached with zinc-sulfate electrode paste in a unipolar arrangement (Lykken, 1959). PROCEDURE

The $S$ sat in an adjustable dental chair, facing a 6-ft-high wooden divider. A shutter in the divider concealed an $8 \times 8$ in. backlighted velum screen. An automatic slide projector and a loudspeaker were positioned behind the divider. Another slide projector was located behind the S's left shoulder, positioned so that its slides were projected directly in front of $S$ on the divider above the shutter.

Ss were told that the experiment was concerned with physiological responding during different states of mind and that those states would be described over the loudspeaker. The $S$ would then concentrate on putting himself into the state of mind described. While he did so, the slide projector behind him would present slides designed to make it harder to concentrate. $\mathrm{S}$ was asked to keep his eyes open, but to try to ignore the distracting slides and concentrate completely on putting himself into the state of mind described by the instructions.

Three series of distracting slides were shown, one slide every $15 \mathrm{sec}$ during each of the three tasks, beginning $15 \mathrm{sec}$ after the task had started. The content of the three series was designed to be distracting by using interesting and unusual slides. Each series contained individual slides with: sexual content; aversive content, consisting of pictures of facial injuries; and more neutral content, including landscapes

Table 1

Heart Rate and Skin Conductance Scores for the First Minute and the Whole of the Three Tasks

\begin{tabular}{|c|c|c|c|c|c|c|}
\hline & & $\begin{array}{c}\text { Pre- } \\
\text { instruction }\end{array}$ & $\begin{array}{l}\text { First Minute } \\
\text { of Task } \\
\text { Minus Pre- } \\
\text { instruction }\end{array}$ & $\mathbf{t}$ & $\begin{array}{c}\text { Whole ( } 3 \text { Min) } \\
\text { Task Minus } \\
\text { Preinstruction }\end{array}$ & $t$ \\
\hline $\begin{array}{l}\text { Heart } \\
\text { Rate } \\
\text { (BPM) }\end{array}$ & $\begin{array}{l}\text { Body } \\
\text { Cognitive } \\
\text { External }\end{array}$ & $\begin{array}{l}84.17 \\
85.22 \\
83.67\end{array}$ & $\begin{array}{l}-0.94 \\
+0.33 \\
-2.50\end{array}$ & $\begin{array}{l}0.67 \\
0.30 \\
2.47^{*}\end{array}$ & $\begin{array}{l}-0.81 \\
-0.33 \\
-2.33\end{array}$ & $\begin{array}{l}0.60 \\
0.37 \\
1.56\end{array}$ \\
\hline 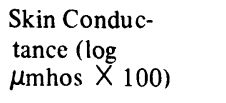 & $\begin{array}{l}\text { Body } \\
\text { Cognitive } \\
\text { External }\end{array}$ & $\begin{array}{l}112.33 \\
113.22 \\
113.60\end{array}$ & $\begin{array}{l}+1.47 \\
+4.33 \\
+2.52\end{array}$ & $\begin{array}{l}2.09 \\
2.03 \\
1.61\end{array}$ & $\begin{array}{l}+1.43 \\
+3.06 \\
+2.45\end{array}$ & $\begin{array}{l}1.57 \\
2.14^{*} \\
1.53\end{array}$ \\
\hline $\begin{array}{l}\text { Skin Conductance } \\
\text { Responses (Number } \\
\text { per Minute) }\end{array}$ & $\begin{array}{l}\text { Body } \\
\text { Cognitive } \\
\text { External }\end{array}$ & $\begin{array}{l}3.17 \\
3.17 \\
3.00 \\
\end{array}$ & $\begin{array}{l}+2.28 \\
+2.94 \\
+3.39\end{array}$ & $\begin{array}{l}2.67 * * \\
3.73 * * * \\
3.26 * * *\end{array}$ & $\begin{array}{l}+0.61 \\
+1.38 \\
+2.00\end{array}$ & $\begin{array}{l}0.92 \\
2.06 \\
2.37 *\end{array}$ \\
\hline
\end{tabular}


and TAT pictures. The three series were equated as closely as possible by using ratings by eight $\mathrm{Ss}$ in a previous experiment. They were combined with the three tasks in all possible ways. ${ }^{1}$

The instructions for the three tasks were presented over the loudspeaker via a tape recorder. One set of instructions directed $S$ to turn his attention toward internal bodily events (body task). $S$ was told to concentrate completely on events that he could feel going on in the interior of his body. A second set of instructions directed him to turn all of his attention to remembering and mentally going over events that had happened to him the day before (cognitive task). A third set of instructions told $S$ to concentrate on looking at a series of six slides that was presented on the screen in front of him (external task). These were chosen in a pilot study to have interesting, but not arousing, content. Each slide was visible for $30 \mathrm{sec}$, being presented synchronously with every other distracting slide.

On all tasks, $\mathrm{S}$ was asked to concentrate his attention completely on the tasks and to avoid anything that would divert his attention. He was assured that he would not have to report about any aspect of the task at any later time.

$\mathrm{S}$ was given $3 \mathrm{~min}$ to concentrate on each task and was then told to stop concentrating and to relax. After a 2-min rest period, the next set of instructions was presented. The three tasks were presented in all possible orders over the experiment. After the third task ended, $\mathrm{S}$ rated how difficult he found each task to be.

Physiological data were scored for the 1 min preceding the onset of each set of instructions (baseline period) and for the three 1 -min periods following the end of the instructions and preceding the instructions to stop (task period). Heart-rate scores were obtained by counting the number of beats per minute occurring during the measurement periods. Mean SC level scores were computed by averaging the log of the reciprocals of skin resistance readings taken $30 \mathrm{sec}$ apart during the periods. Mean SC response scores were obtained by counting the total numbers of deflections in skin resistance larger than 500 ohms occurring during the periods and converting to the number per minute.

\section{RESULTS AND DISCUSSION}

The results for the physiological measures are summarized in Table 1. Analyses of variance revealed that the sequence of presentation of the tasks and the individual slides in the external task had no significant effects.

The right-hand columns of Table 1 indicate that there were no significant HR changes to any of the tasks when the average HR over the whole task is considered. Comparison with the previous Buck et al (1969) results reveals that although the relative order of magnitude of the physiological changes was preserved from the first experiment in all cases, there was an overall change in the direction of arousal on all measures. This effect obscured the HR deceleration to the external task observed in the first experiment, and the only significant changes in this portion of Table 1 were an increase in SC level for the cognitive task and an increase in SC responses for the external task. The physiological responses to the three tasks did not differ significantly on any of the measures.

Further inspection of the data revealed that a differential $H R$ response to the cognitive and external tasks did occur during the first $60 \mathrm{sec}$ of the tasks. As the center portion of Table 1 indicates, the HR deceleration to the external task was significant $(p<.05)$. In addition, the HR response to the cognitive and external tasks was significantly different $(\mathrm{p}<.01)$ when only the first $60 \mathrm{sec}$ were considered. The tasks did not differ from each other on the SC level measure or the SC response measure. All three of the tasks showed an increased number of SC responses during this period.

Questionnaire measures confirmed the previous finding that the body task was rated as being more difficult than either the cognitive task $(p<.01)$ or the external task $(\mathrm{p}<.01)$ and that the cognitive and external tasks did not differ in rated difficulty.

The present experiment replicated the previous study in finding that the cognitive and external tasks were associated with differential HR responding but not differential SC responding, and that the external task was associated with $\mathrm{HR}$ deceleration. However, these findings were found in the present study only for the first $60 \mathrm{sec}$ of the tasks, indicating that the effect may have been weakened by the presence of distraction.

The present experiment did not reveal a significant $\mathrm{HR}$ acceleration to the cognitive task. Assuming that the distracting slides were successful in establishing a need to shut out environmental events, this indicates that the failure to find this acceleration in the first study cannot be explained by a lack of distraction. This result is consistent with the findings of Campos and Johnson in their "no verbalization" conditions and it supports their conclusion that the HR accelerations to rejection tasks in previous studies may have been due to an explicit or covert verbalization requirement. The differential HR responding to the two tasks for the first $60 \mathrm{sec}$ suggests, however, that the cardiac deceleration to acceptance tasks is a reliable phenomenon. It appears that certain influences, such as a verbalization requirement, as in the Campos and Johnson studies, or distraction, as in this experiment, can have effects that override this deceleration. Nevertheless, all these studies appear to indicate that deceleration does occur to acceptance tasks when such influences are minimized.

The other aim of this study was to explore the physiological responses to the task of concentrating on one's internal bodily events under distraction conditions. This task did not lead to cardiac deceleration in this study as it had in the previous experiment. Also, this task was again rated to be more difficult than the other tasks, so that its position along the acceptance-rejection continuum remains unclear.

\section{REFERENCES}

BUCK, R., MILLER, R. E. \& CAUL, W. F. Heart rate and skin conductance responding during three attention-direction tasks. Psychononic Science, 1969, 15, 291-292.

CAMPOS, J. J., \& JOHNSON, H. J. The effects of verbalization instructions and visual attention on heart rate and skin conductance. Psychophysiology, 1966, 2, 305-310.

CAMPOS, J. J., \& JOHNSON, H. J. The effect of affect and verbalization instructions of directional fractionation of autonomic response. Psychophysiology, 1967, 3, 245-290.

GIBSON, D., \& HALL, M. K. Cardiovascular change on mental task gradient. Psychonomic Science, 1966, 6, 245-246.

JOHNSON, H. J., \& CAMPOS, J. J. The effect of cognitive tasks and verbalization instructions on heart rate and skin conductance. Psychophysiology, 1967, 4, 143-150.

LACEY, J. I. Psychophysiological approaches to the evaluation of psychotherapeutic process and outcome. In F. A. Rubensttin and M. B. Parloff (Eds.), Research in psychotherapy. Washington, D.C: American Psychological Association, 1959. Pp. 000-000.

LACEY, J. I., KAGAN, J., LACEY, B. C., \& MOSS, H. A. The visceral level: Situational determinants and behavioral correlates of autonomic response. In P. Knapp (Ed.), Expression of the emotions in man. New York: International Universities, 1963. Pp. 000-000.

LYKKEN, D. T. Properties of electrodes used in electrodermal measurement. Journal of Comparative \& Physiological Psychology, 1959, 52, 629.634.

STEELE, W. G., \& KOONS, P. B. Cardiac response to mental arithmetic under quiet and white noise distraction. Psychonomic Science, $1968,11,273-274$. NOTE

1. In order for the kind of visual distraction used in this experiment to be successful, the $S$ should neither completely avoid looking at the distr- -ion slides nor should he attend exclusively to the slides without concentrating on the tasks. An attempt was made to determine the reaction of the Ss to the slides by watching them over a 
concealed closed-circuit television system. Unfortunately, technical difficulties with the camera forced the abandonment of this attempt, and only six Ss could be observed carefully. Of these. five glanced momentarily at the majority of the distracting slides, and one did not appear to glance at any of the distracting slides. No obvious differences in physiological responses were apparent between these $\mathrm{Ss}$ or between periods in which glances did or did not occur, although the number of observations was, of course, too small for an adequate analysis.

\title{
The effect of verbal and pictorial presentation on class-inclusion competence and performance
}

\author{
J. RICHARD JENNINGS* \\ University of California, Berkeley, Calif. 94720
}

Wohlwill (1968) reported that young children correctly answer more class-inclusion questions when these items are presented entirely verbally as compared to when verbal presentation is supplemented by pictures. Wohwill interpreted these results as showing that perceptual factors influence the ability to apply class-inclusion operations. Wohlwill, however, did not explore adequately the cognitive basis of the children's answers. In the present study of 78 kindergarten-to-third-grade boys, cognitively justified class-inclusion answers were facilitated by pictorial rather than verbal presentation, particularly among older boys. Verbal items produced some facilitation in kindergarten boys, but only for unjustified correct answers.

Wohlwill (1968) compared children's answers to a standard class-inclusion presentation utilizing pictures with their answers to a purely verbal presentation of items, such as, "Suppose I have 7 dogs and 3 horses, do I have more animals or more dogs?" The children (mean ages: 4 years 11 months to 6 years 10 months) gave more correct solutions to the purely verbal items than to the pictorial items. Thus, the verbal procedure seemed to produce evidence of class inclusion ability occurring at a younger age than had previously been found (Inhelder \& Piaget, 1964, for example).

Wohlwill (1968) maintained that the difference between verbal and pictorial class-inclusion performance was due to the high number of errors caused by misleading cues present in pictorial class inclusion. Pictorial presentation, he argues, induces a perceptual set to compare the pictured subsets. When one subset has more

\footnotetext{
*Thanks are due Dr. Jonas Langer for his assistance and encouragement in connection with this study and Dr. Joachim $\mathrm{F}$. Wohlwill for his critical comments on an earlier version of this paper. I would also like to thank the staff and pupils of Eldridge Elementary School and the Hayward Unified School District for their cooperation. This report represents a partial report of a doctoral dissertation done under the supervision of Dr. Richard S. Lazarus at the University of California, Berkeley. The author was a research trainee for the U.S. Rehabilitation Services Administration (Grant RH-4) when the study was conducted. The current address of the author is Department of Experimental Psychophysiology, Walter Reed Army Institute of Research, Washington, D.C. 20012.
}

members than the other subset, the resulting perceptual disparity causes erroneous solutions, e.g., more dogs than animals. Verbal presentation, it is further argued, weakens this distorting "subclass comparison set." Wohlwill therefore hypothesizes that verbal items should be answered correctly more often than pictorial items.

Wohlwill's evidence and subsequent work by Ayr \& Youniss (1970) indicate that perceptual disparity of the subsets does lead to errors in pictorial class inclusion. The facilitating effect of verbal presentation on class inclusion competence, however, can be questioned. Wohlwill (1968) failed to present complete data on the child's understanding of verbally presented questions and on the child's justification for his answers.

With regard to the child's understanding, Wohlwill has assumed that verbal presentation clearly poses the class inclusion problem in which two subsets, A 1, A2, exhaustively compose a superordinate, $B$, such that $A 1+A 2=B$. However, if the child does not understand that the verbal questions refer only to the subsets given him, e.g., seven dogs (A1) and three horses (A2), it is difficult to interpret a child's correct response. As Wohlwill (1968) notes, the child may either be making a global superordinate-subclass judgment, B $>$ A1, e.g., there are more animals in the world than dogs, or be judging whether one subclass is larger than its complement, $\mathrm{A} 1<\overline{\mathrm{A}} 1$, e.g., are there more dogs or more things that aren't dogs? In either case, the child's correct response is based on a misrepresentation of the class-inclusion question.

The child's justifications must be considered in order to separate correct operational solutions based on an adequate understanding of the question from correct answers based on misunderstanding. The operational child understands that $\mathrm{B}=\mathrm{A} 1+\mathrm{A} 2$ and can operate on these concepts, producing such combinations as $\mathrm{B}-\mathrm{A} 1=\mathrm{A} 2$, e.g., taking the dogs away from the animals leaves the horses. The preoperational child may be able to represent or misrepresent these classes to himself, but he cannot operate on them.

Wohlwill's method and interpretation by ignoring the child's understanding and justifications is unable to distinguish between correct solutions based on operative competence and correct answers based on misrepresentation of the questions.

In the present inquiry the child's justifications and understanding of verbal and pictorial class inclusion questions were examined as part of a larger study (Jennings, 1969). Seventy-eight boys were tested. Their mean ages were: kindergarten, 5 years 11 months; first grade, 7 years 1 month; second grade, 8 years, 2 months; and third grade, 9 years 6 months.

Ss received either the verbal condition or the pictorial condition. The verbal condition was given to 10 kindergarten, 12 first-grade, 10 second-grade, and 9 third-grade boys. The pictorial condition was given to 10 kindergarten, 10 first-grade, 11 second-grade, and 6 third-grade boys.

The verbal condition consisted first of two test items drawn directly from Wohlwill's items: (1) "Suppose I have 7 dogs and 3 horses, do I have more animals or more dogs?" (2) "Suppose I have 4 owls and 2 pigeons, do I have more birds or more owls?" These were followed by two items drawn directly from Inhelder \& Piaget (1964): (3) "Suppose I have a bunch of 8 different flowers and a bunch of 8 daisies, do I have more flowers or more daisies?" (4) "Suppose I have a bunch of 4 red daisies and a bunch of 4 daisies that are other colors, do I have more red daisies or more daisies?"

In the pictorial condition the same two Inhelder-Piaget items were followed by two different Wohlwill items: (3) "3 strawberries and 2 tomatoes. Are there more strawberries or more things to eat?" (4) "5 butterflies and 3 birds. Are there more butterflies or more things that fly?" Pictorial items portrayed the two subsets grouped separately on a Masonite display board (see Wohlwill, 1968, Condition B, Experiment III). The use of the same 